\title{
RESISTÊNCIA DE BIOMPHALARIA GLABRATA À INFECÇÃO PELO SCHISTOSOMA MANSONI:VARIAÇÕES NO PERÍODO PRÉ-PATENTE E NA COMPATIBILIDADE
}

\author{
Carlos Tito Guimarães, Delza de Moura Soares, \\ Zilton de Araújo Andrade e Cecília Pereira de Souza
}

\begin{abstract}
Biomphalaria glabrata de Belo Horizonte, Minas Gerais, Brasil, criada no laboratório, apresenta $90 \%$ de taxa de infecção com 20 miracídios da cepa LE, autóctone. O periodo pré-patente normal varia de 5 a 7 semanas enquanto 5 a $10 \%$ dos moluscos expostos não eliminam cercárias. Os descendentes de exemplares negativos foram novamente submetidos à infecção individual com 20 miracídios. A média de infecção da $F_{14}$ a $F_{20}$ foi de $43,6 \%$. Cortes bistológicos de moluscos da $F_{12}, F_{14}$ e $F_{15}$ mostraram reações teciduais nos exemplares eliminando menos de 10 cercárias. Um período pré-patente prolongado, 17 a 32 semanas, foi observado em 35 (17,9\%) dos 195 exemplares infectados. Os indices de cercárias da $F_{12}, F_{13}$ e $F_{15}$ baixaram de extremamente compativeis (classe VI) para muito compativeis e compatíveis (classes Ve III) mostrando a compatibilidade menor dos moluscos selecionados.
\end{abstract}

Palavras-chaves: Biomphalaria glabrata. Resistência. Compatibilidade. Schistosoma mansoni.

A importância de Biomphalaria glabrata como hospedeira intermediária de Schistosoma mansoni no Brasil é bastante conhecida e alguns estudos têm demonstrado a sua alta suscetibilidade e compatibilidade à infecção com esse parasita16. Entretanto, existem populações dessa espécie pouco suscetíveis ao parasita e alguns aspectos da evolução parasitária nesses moluscos com exceção das reações histopatológicas5 67 são pouco conhecidos.

Richards e cols 13 verificaram em moluscos pouco suscetíveis a presença de esporocistos com localização ectópica na região cefalopodal e a ocorrência de eliminação tardia de cercárias nessa região. Lewis e cols ${ }^{4}$ observaram em descendentes de cruzamento de moluscos resistentes e suscetíveis, um retardo de até 10 meses no período pré-patente da infecção com S. mansoni.

No presente trabalho, procurou-se através de infecções repetidas selecionar indivíduos resistentes de uma população suscetível e

Centro de Pesquisas "René Rachou"/FIOCRUZ, Belo Horizonte, MG e Centro de Pesquisas Gonçalo Moniz/ FIOCRUZ, Salvador, BA, Brasil.

Endereço para correspondência: Dr. Carlos Tito Guimarães. Centro de Pesquisas "René Rachou"/FIOCRUZ. Av. Augusto de Lima 1715, 30190-002 Belo Horizonte, MG, Brasil. Fax: (031) 295-3115.

Recebido para publicação em 25/11/96. estudar a estabilidade da resistência em gerações subsequentes para conhecer melhor alguns aspectos da evolução parasitária nesses moluscos.

\section{MATERIAL E MÉTODOS}

Foram utilizados exemplares de B. glabrata criados no laboratório, descendentes de caramujos coletados no Barreiro de Cima (Belo Horizonte, MG, Brasil). Esses moluscos são mantidos no Laboratório de Malacologia do Centro de Pesquisas "René Rachou" há mais de 20 anos. A cepa de $S$. mansoni utilizada foi a LE de Belo Horizonte, mantida no laboratório há mais de 20 anos

De um grupo de 400 exemplares submetidos à infecção em massa com S. mansoni18 e reinfecção com um total de 116 miracídios por caramujo, em fevereiro de 1990 foram selecionados 8 exemplares negativos em exames realizados após exposição a luz por 30 minutos e após esmagamento entre lâminas de vidro, decorridos 30, 35 e 40 dias da exposição a miracídios. Destes moluscos foram obtidos 130 descendentes que se constituíram na geração $F_{1}$. Ao atingirem o diâmetro entre $4-7 \mathrm{~mm}, 100$ destes exemplares foram submetidos à infecção e reinfecção com 20 miracídios por molusco. Dos exemplares negativos em exames semanais após 30 a 365 dias foram coletadas as desovas para obtenção das gerações seguintes. Repetiu-se essa metodologia para obtenção e 
Guimarães CT, Soares DM, Andrade ZA, Souza CP. Resistência de Biomphalaria glabrata à infecção pelo Schistosoma mansoni: variações no perído pré-patente e na compatibilidade. Revista da Sociedade Brasileira de Medicina Tropical 30:273-278, jul-ago, 1997.

infecção das gerações seguintes até a $F_{20}$, examinada até março de 1996. O total de moluscos selecionados e expostos a miracídios da $F_{1}$ a $F_{20}$ foi de 1801 exemplares.

Para cada experimento paralelamente foi feito controle de infecção utilizando-se 20 moluscos da população do laboratório, com o diâmetro de $4-7 \mathrm{~mm}$. Após a infecção os exemplares foram mantidos individualmente em frascos cilíndricos de vidro transparente com $120 \mathrm{ml}$ de água comum de torneira, em sala com temperatura média de $25 \pm 2^{\circ} \mathrm{C}$.

Nas gerações $F_{12}, F_{13}$ e $F_{15}$ foram feitas contagens de cercárias dos exemplares positivos, em cinco alíquotas de $1 \mathrm{ml}$ de água retirada dos aquários de manutenção, 3 vezes por semana, antes da troca de água até ocorrer a morte de todos os moluscos infectados. Oito exemplares da $F_{15}$, negativos após 264 dias da primeira exposição foram novamente expostos a 20 miracídios da cepa LE de $S$. mansoni.
Os moluscos foram alimentados com ração para roedores, triturada, acrescida de 10\% de carbonato de cálcio e folhas frescas de alface.

Os índices de compatibilidade dos moluscos com o parasito foram calculados de acordo com a técnica de Frandsen ${ }^{1}$ usando a fórmula: total de cercárias produzidas dividido pelo número de moluscos expostos e multiplicado por 100 (TCP/100). Os resultados obtidos foram comparados com os dados de tabela de Frandsen 1 , que contém seis classes de compatibilidade além de uma resistente.

Exemplares das gerações $\mathrm{F}_{12}, \mathrm{~F}_{14}$ e $\mathrm{F}_{15}$, eliminando cercárias ou não, foram fixados e submetidos a cortes seriados para estudos histológicos, usando a mesma técnica descrita em trabalho anterior ${ }^{17}$ a qual consistiu em fixação em líquido de Bouin, inclusão em parafina, com secções coradas pela hematoxilina e eosina.

\section{RESULTADOS}

A taxa de infecção dos moluscos da $\mathrm{F}_{1}$ foi de $94,6 \%$. Da $\mathrm{F}_{1}$ a $\mathrm{F}_{20}$ as taxas de infecção variaram muito e a taxa média de infecção da $\mathrm{F}_{14}$ a $\mathrm{F}_{20}$, cujos exemplares foram examinados por mais de 17 semanas foi de 43,6\%. Os índices de compatibilidade dos moluscos das gerações, $\mathrm{F}_{12}, \mathrm{~F}_{13}$ e $\mathrm{F}_{15}$ e dos grupos de controle são mostrados na Tabela 1. A compatibilidade dos moluscos à infecção com $S$. mansoni baixou após várias gerações, da classe VI para as classes V e III (Tabela 1) mostrando que houve diminuição da média de cercárias eliminadas por molusco. Os períodos pré-patentes das gerações $F_{14}$ a $F_{20}$ variaram de 5 a 32 semanas (Figura 1). O retardo do período pré-patente, de 17 a 32 semanas (4 a 7 meses) foi observado em 35 (17,9\%) exemplares infectados. O total de caramujos expostos da $\mathrm{F}_{14}$ a $\mathrm{F}_{20}$ foi de 564 , dentre os quais 195 (34,5\%) eliminaram cercárias. Dentre oito exemplares adultos da $\mathrm{F}_{15}$ expostos pela segunda vez a miracídios, nenhum eliminou cercárias.

Os estudos a nível histológico mostraram focos de proliferação e diferenciação de numerosos esporocístos em vários órgãos, sem qualquer reação aparente por parte do hospedeiro, nos moluscos eliminando mais de 100 cercárias. Este quadro era semelhante ao observado nos moluscos controles e os órgãos mais envolvidos foram as glândulas digestivas (Figura 2) e o ovoteste (Figura 3). Os moluscos

Tabela 1- Níveis diferentes de compatibilidade de Biomphalaria glabrata infectada com Schistosoma mansoni.

\begin{tabular}{lccl}
\hline $\begin{array}{l}\text { Geração de } \\
\text { moluscos }\end{array}$ & TPC/100 & \multicolumn{1}{c}{ Compatibilidade } \\
\cline { 3 - 4 } F 12 & & classe & descrição \\
C & 360.314 & muito compatível \\
F 13 & 920.175 & VI & extremamente compatível \\
C & 323.306 & V & muito Compatível \\
F 15 & 1.086 .495 & VI & extremamente compatível \\
C & 100.045 & III & compatível \\
\hline
\end{tabular}

$\mathrm{TPC} / 100=$ Total de cercárias produzidas por 100 moluscos expostos; $\mathrm{C}=$ controle, moluscos não selecionados do laboratório. 
Guimarães CT, Soares DM, Andrade ZA, Souza CP. Resistência de Biomphalaria glabrata à infecção pelo Schistosoma mansoni: variações no período pré-patente e na compatibilidade. Revista da Sociedade Brasileira de Medicina Tropical 30:273-278, jul-ago, 1997.

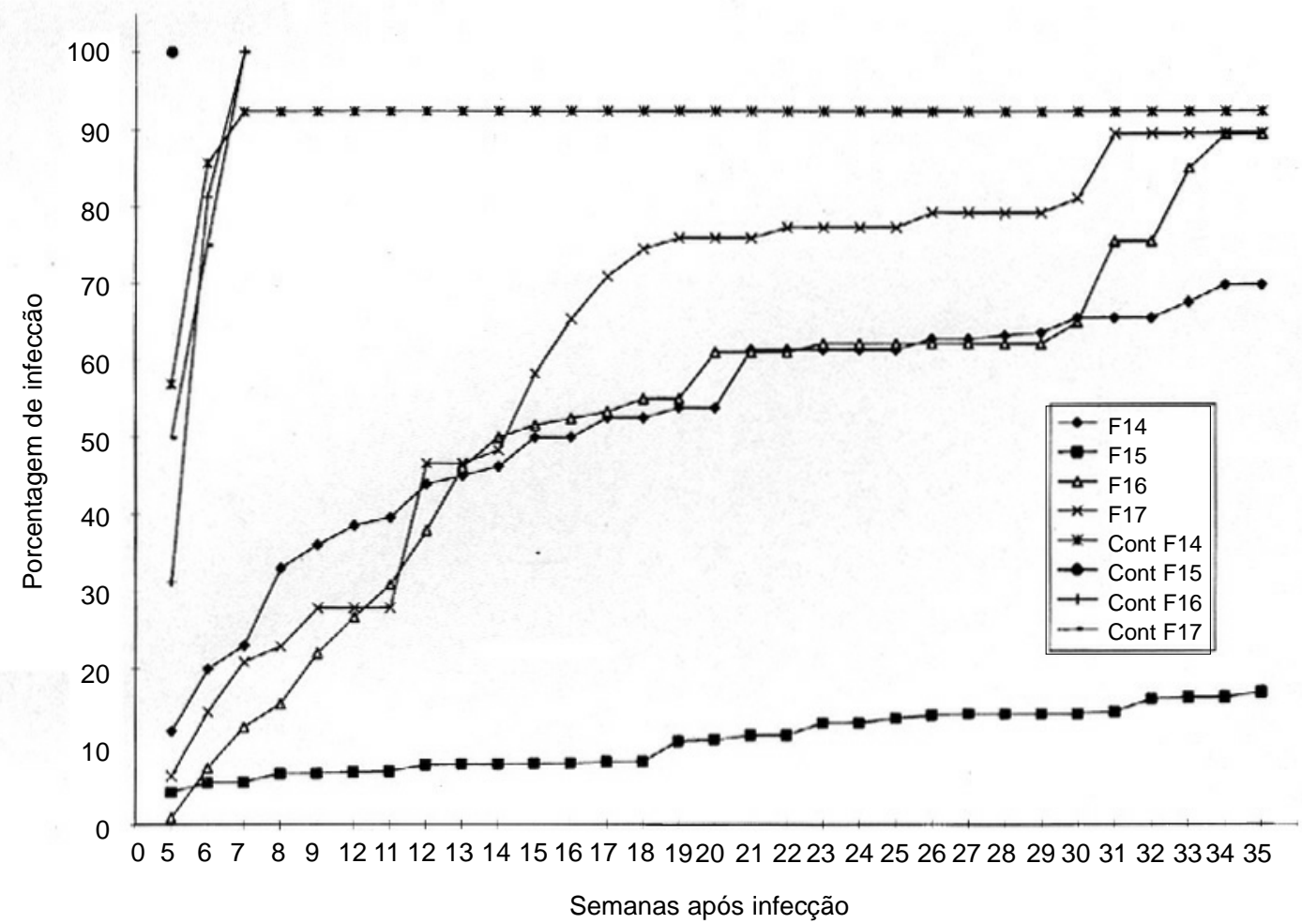

Figura 1 - Periodos pré-patentes de gerações de Biomphalaria glabrata, parcialmente resistentes e suscetíveis à infecção com Schistosoma mansoni.

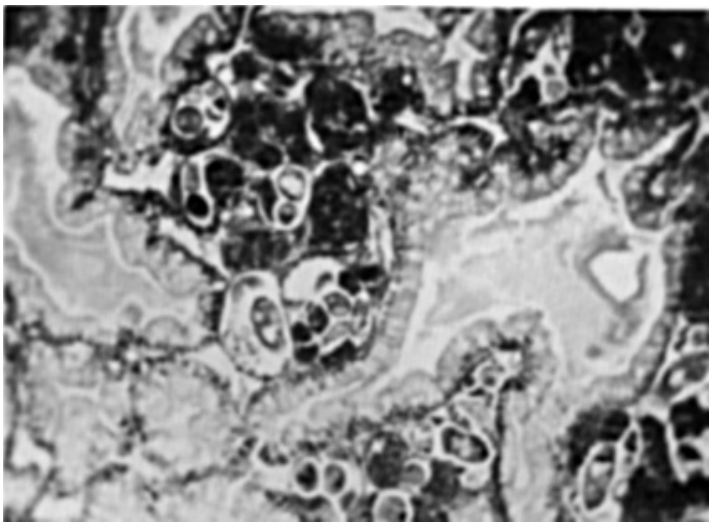

Figura 2 - No interstício das glândulas digestivas aparecem esporocístos formando grumos basófilos em fase inicial de proliferacão e cercárias jâ bem diferenciadas, sem qualquer reação evidente por parte do hospedeiro. Hematoxilina-eosina, $160 \mathrm{X}$.

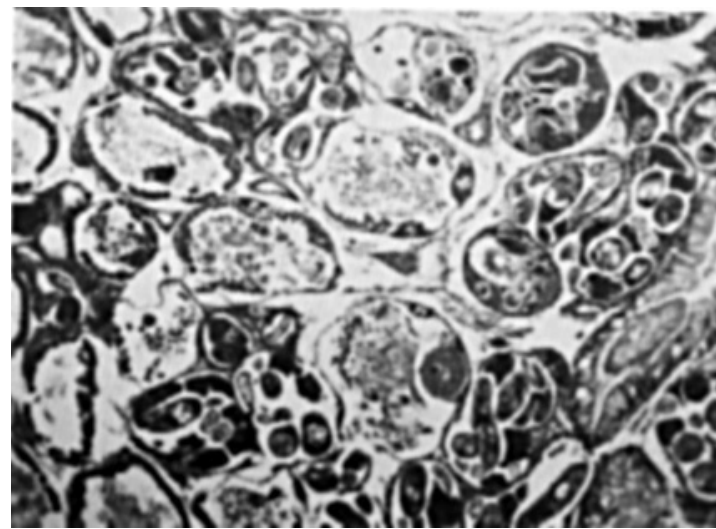

Figura 3 - Região do ovoteste mostrando túbulos contendo
espermatozóides e óvulos e muitas cercárias em desenvolvimento, tanto no intersticio, como no interior dos túbulos, mas sem qualquer reação nos tecidos envolvidos. Hematoxilina-eosina $160 \mathrm{X}$. 
Guimarães CT, Soares DM, Andrade ZA, Souza CP. Resistência de Biomphalaria glabrata à infecção pelo Schistosoma mansoni: variações no período pré-patente e na compatibilidade. Revista da Sociedade Brasileira de Medicina Tropical 30:273-278, jul-ago, 1997.

da $\mathrm{F}_{12}$ e $\mathrm{F}_{15}$, que eliminaram até 10 cercárias após cada exposição mostraram além de esporocistos em desenvolvimento sem reação tecidual, outros focos em que os parasitas apareciam no seio de proliferação de amebócitos, os quais

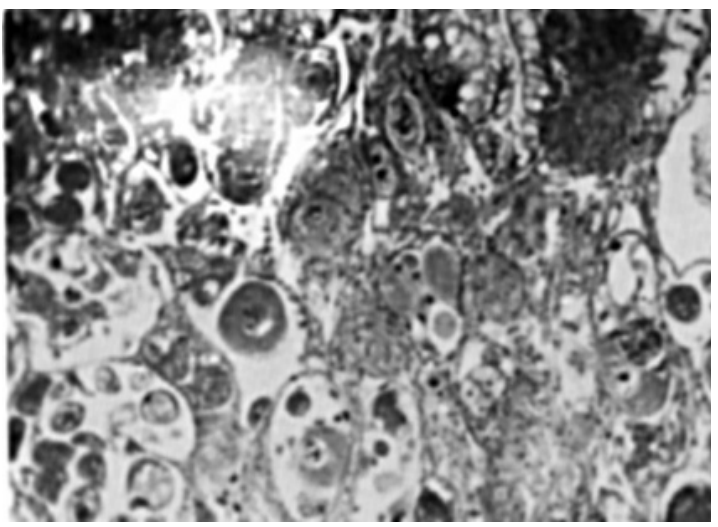

Figura 4 - Ovoteste de um caramujo eliminando poucas cercárias Reacôes encapsulantes (granulomatosas) aparecem ao lado de proliferaçao difusa de amebocitos e de grupos de cercarias que se desenvolvem sem reação aparente em torno. Hematoxilina-eosina, $160 \mathrm{X}$. formavam lesões encapsulantes no centro das quais os esporocistos exibiam vários graus de desintegração. As reações mais evidentes foram notadas no ovoteste (Figura 4) e na região dos túbulos renais (Figura 5)

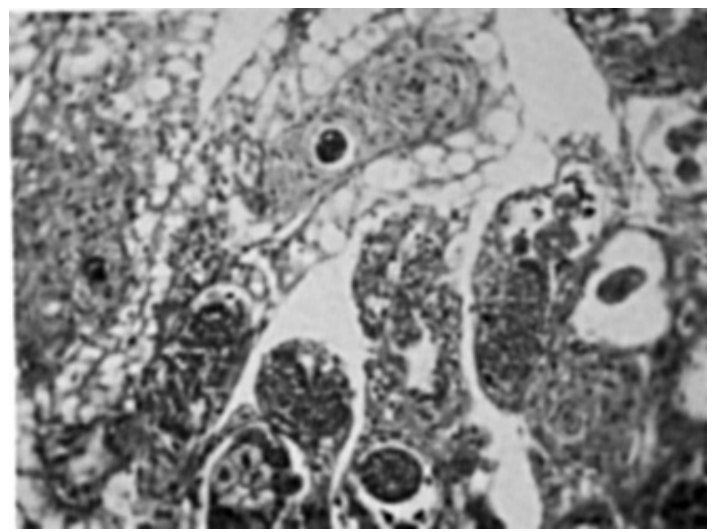

Figura 5 - Região dos túbulos renais onde se vêm as células tubulares claras, as zonas com proliferação bem inicial de esporocistos e os focos com reaçoes encapsulantes em torno de elementos parasitários em desintegração. Hematoxilina-eosina, $160 \mathrm{X}$

\section{DISCUSSÃO}

Souza e cols16 em estudo da compatibilidade de três espécies de Biomphalaria hospedeiras do S. mansoni no Brasil, observaram que a população de B. glabrata de Belo Horizonte, MG, mantida no laboratório era altamente compatível com três cepas do parasita de localidades diferentes. Os moluscos infectados eliminaram número elevado de cercárias ao contrário de B. straminea e B. tenagophila. Estudos comparativos, a nível histológico17 mostraram ainda a presença de numerosos esporocistos de $S$. mansoni, sem reação tecidual, em vários órgãos de $B$. glabrata, enquanto em $B$. tenagophila e B. straminea foram observadas numerosas reações de encapsulamento de larvas do trematódeo em vários órgãos e retardo do período pré-patente. Entretanto, essa população de $B$. glabrata é geneticamente heterogênea, pois, cerca de 5\% dos moluscos ou não se infectam ou apresentam retardo no período pré-patente. A seleção a partir dos moluscos que não se infectaram, mostrou que mesmo entre indivíduos selecionados existe grande variabilidade genética para o fator suscetibilidade. Segundo Paraense e Corrêa', a variação na suscetibilidade seria um aspecto da variação intra-específica do molusco e os graus de suscetibilidade dependeriam da freqüência relativa dos genótipos resistentes e suscetíveis em cada população. Para Lewis e cols 4 muitas interações hospedeiro-parasita diferentes ocorrem com diferentes combinações de populações de B. glabrata e S. mansoni. Algumas combinações genéticas ajudam o parasita a desenvolver e proliferar porque o molusco não o reconhece como corpo estranho. Em outras combinações o parasita é reconhecido e rapidamente encapsulado pelos hemócitos e fagocitado em poucos dias3 5671314

Paraense e Corrêa10 11, registraram um retardo de 135 dias no período pré-patente de $B$. tenagophila e de 90 dias em molusco do Uruguai, semelhante à $B$. straminea. De fato, no Brasil os maiores retardos nos períodos prépatentes foram registrados em $B$. tenagophila e B. stramined 101117 . 
Guimarães CT, Soares DM, Andrade ZA, Souza CP. Resistência de Biomphalaria glabrata à infecção pelo Schistosoma mansoni: variações no período pré-patente e na compatibilidade. Revista da Sociedade Brasileira de Medicina Tropical 30:273-278, jul-ago, 1997.

Richards e cols13 observaram em seleção de moluscos para o caráter resistência que na $\mathrm{F}_{12}$ $90 \%$ dos moluscos eram considerados resistentes, mas em exame para evidenciar ou não a resistência foram observados esporocistos pequenos com localização ectópica na região cefalopodal e a eliminação tardia de cercárias, nessa região.

Lewis e cols 4 em estudo de moluscos $B$. glabrata obtidos de cruzamento de exemplares suscetíveis e resistentes, observaram que 19,0\% dos moluscos apresentavam retardo no período pré-patente, que durava até 10 meses.

Larson e cols 2 conseguiram através da técnica de reação em cadeia da polimerase (RAPDPCR) detectar o perfil do DNA de exemplares de $B$. glabrata, resistentes e suscetíveis à infecção com S. mansoni.

Em nossos experimentos 17,9\% dos moluscos infectados eliminaram cercárias após 4 a 7 meses (17 a 32 semanas) da infecção, resultado semelhante ao obtido por Lewis e cols 4 . Um exemplar que eliminou cercárias após 7 meses de infecção estava com 315 larvas no primeiro dia de eliminação. Alguns exemplares infectados eliminaram menos de 10 cercárias por exposição, ao passo que outros eliminavam 100, 300 ou mais cercárias. O estudo histológico dos moluscos eliminando menos de 10 cercárias $\left(F_{12}\right.$ e $\left.F_{15}\right)$ mostrou reações teciduais de encapsulamento de larvas mais severas após 30 dias de infecção (Figuras 4 e 5). Nos exemplares eliminando mais de 100 cercárias, aparentemente não foram observadas reações teciduais (Figuras 2 e 3 ). Como o número de cercárias eliminadas pelos moluscos parcialmente resistentes foi menor do que o dos altamente suscetíveis a sobrevivência desses exemplares foi maior, o que está de acordo com as observações de Paraense8.

Em moluscos de Belo Horizonte, com infecção natural já foi observado o período de eliminação de cercárias durante 7 meses 15 .
Portanto em B. glabrata de Belo Horizonte, tanto o período pré-patente como o patente podem durar vários meses. De fato, nesse laboratório, em moluscos coletados no campo e mantidos no laboratório já foi observado período pré-patente até de 4 meses, o que pode estar relacionado a temperaturas mais baixas 19 ou à resistência à infecção com o trematódeo.

Em seis anos de experimentos, a taxa de infecção baixou cerca de 50\% (de 95,0 para 43,6\%). O período pré-patente normal de 5 a 7 semanas prolongou até 32 semanas ( 7 meses). Também as compatibilidades dos exemplares infectados diminuiram gradualmente passando de extremamente compatíveis (classe VI) para compatíveis (classe III), até a geração $\mathrm{F}_{15}$. Portanto a compatibilidade de $B$. glabrata da $\mathrm{F}_{15}$ tornou-se comparável à de $B$. tenagophila de Belo Horizonte, Pampulha, infectada com as cepas SJ e AL (classe III)16.

Esses estudos mostraram aspectos pouco conhecidos sobre a potencialidade de $B$. glabrata como vetora de esquistossomose, e demonstraram que o molusco parcialmente resistente pode manter o parasita em seu organismo por vários meses sem eliminar cercárias e sem dano aparente para ambos e que a soma dos períodos pré-patente e patente da infecção pode durar mais de 12 meses. Por outro lado, a seleção de moluscos totalmente resistentes, cujos descendentes também fossem totalmente resistentes, até a geração $\mathrm{F}_{20}$ não foi possível. Os moluscos que não se infectaram na fase jovem mostraram-se resistentes à infecção na fase adulta, o que está de acordo com as observações de Richards12 .

Estudos empregando técnicas de biologia molecular ${ }^{2}$ serão efetuados com os moluscos negativos da $\mathrm{F}_{20}$ em diante na tentativa de detectar o perfil do DNA dos exemplares resistentes, parcialmente resistentes e suscetiveis à infecção com S. mansoni.

\section{SUMMARY}

Biomphalaria glabrata from Belo Horizonte, Minas Gerais, Brazil, reared in laboratory, has a level of infection of $90 \%$ when exposed to 20 miracidia of the autochthonous LE strain. The prepatent period was of 5 to 7 weeks whereas 5 to $10 \%$ of exposed snails do not shed cercariae. The eggs of negative snails were collected and the progeny was again submitted to individual infection with 20 miracidia. The mean of infection from $F_{14}$ to $F_{20}$ was of $43.6 \%$. Histological sections from $F_{12}, F_{14}$ and $F_{15}$ snails showed tissue reactions in those specimens shedding less than 10 cercariae. A prepatent period of 17 to 32 weeks was observed in 35 (17.9\%) of 195 infected snails. The index of cercariae of control was 
Guimarães CT, Soares DM, Andrade ZA, Souza CP. Resistência de Biomphalaria glabrata à infecção pelo Schistosoma mansoni: variações no periodo pré-patente e na compatibilidade. Revista da Sociedade Brasileira de Medicina Tropical 30:273-278, jul-ago, 1997.

extremely compatible and for $F_{12}, F_{13}$ and $F_{15}$ snails varied from very compatible class $V$ to compatible class III, showing less compatibility in selected snails.
Key-words: Biomphalaria glabrata. Resistance. Compatibility. Schistosoma mansoni

\section{REFERÊNCIAS BIBLIOGRÁFICAS}

1. Frandsen F. Discussion of the relationships between Schistosoma and their intermediate hosts, assessment of the degree of host-parasite compatibility and evaluation of Schistosome taxonomy. Zeitschrift fur Parasitenkunde 58:275$296,1979$.

2. Larson SE, Andersen PL, Miller AN, Cousin CE, Richards CS, Lewis FA, Knight M. Use of RAPDPCR to differentiate genetically defined lines of an intermediate host of Schistosoma mansoni, Biomphalaria glabrata. Journal of Parasitology 82:237-244, 1996.

3. Lie KJ, Jeong KH, Heyneman D. Molluscan host reactions to helminthic infection. In Immune response in parasitic infections, EJ Soulsby, Ed. CRC Press, Boca Raton FL, 1987.

4. Lewis FA, Richards CS, Knight M, Cooper LA, Clark B. Schistosoma mansoni: Analysis of an unusual infection phenotype in the intermediate host snail Biomphalaria glabrata. Experimental Parasitology 77:349-361, 1993.

5. Loker ES, Bayne CJ, Bucley PM, Kruse KT. Ultrastructure of encapsulation of Schistosoma mansoni mother sporocysts by hemocytes of juveniles of $10 \mathrm{R} 2$ strain of Biomphalaria glabrata. Journal of Parasitology 68:84-94, 1982.

6. Newton WL. The comparative tissue reaction of two strains of Australorbis glabratus. Journal of Parasitology 38:362-366, 1952.

7. Pan CT. Generalized and focal tissue responses in the snail Australorbis glabratus, infected with Schistosoma mansoni. Annals of New York Academy Science 113:475-485, 1963.

8. Paraense WL. Planorbídeos hospedeiros intermediários do Schistosoma mansoni. In: Cunha AS (ed) Esquistossomose mansoni, p. 1330,1970

9. Paraense WL, Corrêa LR.Variation in susceptibility of populations of Australorbis glabratus to a strain of Schistosoma mansoni. Revista do Instituto de Medicina Tropical de São Paulo 5:1522, 1963 .

10. Paraense WL, Corrêa LR. Observations on two biological races of Schistosoma mansoni.
Memórias do Instituto Oswaldo Cruz 76:287-291, 1981.

11. Paraense WL, Corrêa LR. A potencial vector of Schistosoma mansoni in Uruguay. Memórias do Instituto Oswaldo Cruz 84:281-288, 1989.

12. Richards CS. Influence of snail age on genetic variations in susceptibility of Biomphalaria glabrata for infection with Schistosoma mansoni. Malacologia 25:493-502, 1984.

13. Richards CS, Knight M, Lewis FA. Genetics of Biomphalaria glabrata and its effect on the outcome of Schistosoma mansoni infection. Parasitology Today 8:171-174, 1992.

14. Richards CS, Merritt JW Jr. Genetic factors in the susceptibility of juvenile Biomphalaria glabrata to Schistosoma mansoni infection. The American Journal of Tropical Medicine and Hygiene 21:425434, 1972.

15. Souza CP, Araujo N, Jannotti-Passos LK, Guimarães CT. Production of Schistosoma mansoni cercariae by Biomphalaria glabrata from a focus in Belo Horizonte, Minas Gerais. Revista do Instituto de Medicina Tropical de São Paulo 36:485-489, 1994.

16. Souza CP, Jannotti-Passos LK, Freitas JR. Degree of host-parasite compatibility between Schistosoma mansoni and their intermediate molluscan hosts in Brazil. Memórias do Instituto Oswaldo Cruz 90:5-10, 1995a.

17. Souza CP, Cunha RCP, Andrade ZA. Development of Schistosoma mansoni in Biomphalaria tenagophila, Biomphalaria straminea and Biomphalaria glabrata. Revista do Instituto de Medicina Tropical de São Paulo 37:201-206, 1995b.

18. Standen OD. Experimental infection of Australorbis glabratus with Schistosoma mansoni. Individual and mass infection of snails and the relationship of infection to temperature and season. Annals of Tropical Medicine and Parasitology 46:48-53, 1952.

19. Stirewalt MA. Effect of snail maintenance temperature on development of Schistosoma mansoni. Experimental Parasitology 3:504-506, 1954. 